\title{
Human Beings - The Mind and the Body: Wittgensteinian-Aristotelian Reflections
}

\author{
PETER M.S. HACKER, OXFORD
}

\section{Prolegomenon}

Wittgenstein dominated analytic philosophy from the 1920s until the 1970s. His followers were numerous, his influence was extensive and even those who were not attracted by his thought were forced to orient themselves by reference to the landmarks he had established. After the 1970s, his influence progressively waned, first in philosophy of logic and language, where Fregean and Tarskian influences came to predominate, and later in philosophy of mind, which engaged in speculative debates concerning brain/mind relationships, on the one hand, and the 'mysteries of consciousness', on the other. It is striking that this turn against Wittgenstein's philosophy was not accompanied by a firm understanding, let alone by an argued refutation, of his grammatical overviews. Rather, these developments in the last decades of the twentieth century exemplified the philosophical scientism of our times.

While Wittgenstein's influence waned, Wittgensteinian scholarship continued to flourish for another two or three decades. By the end of the century, however, Wittgensteinian scholarship itself was in danger of deteriorating into an arid scholasticism, characterized by fruitless inward looking debates concerning precisely what sort of nonsense the author of the Tractatus produced and whether the results of his later labours were anything more than person-relative therapies. Unsurprisingly, philosophers who were unfamiliar or unsympathetic with his work felt increasingly safe in by-passing it either in silence or in contempt.

This is a sad state of affairs - for the ideas of the greatest philosopher of the last two centuries are in effect being shelved. I do not doubt that they will be revived in the fullness of time - if our subject survives; if our civilization survives; if our planet survives. However, contemporary philosophers with a serious interest in the works of Wittgenstein have much with which to busy themselves, despite the fact that Wittgenstein is currently being sidelined. The tasks I have in mind are of two kinds: those pertaining to Wittgenstein scholarship, and those concerned with Wittgenstein- 
inspired philosophy.

The tasks of Wittgenstein scholarship bifurcate into editorial work that remains to be done and exegetical labours. Despite the great achievements of the Bergen electronic edition of Wittgenstein's Nachlass, and Joachim Schulte's magnificent Kritisch-genetische edition of the Philosophische Untersuchungen, there is still substantial editorial work to be done or redone, especially on the mathematical manuscripts. As far as clarification of Wittgenstein's philosophy is concerned, it seems to me that the greatest unmined goldfields he left us are in his writings on philosophy of mathematics. This is the domain in which his work is, I think, least understood, and where painstaking exegesis of his writings is needed.

The tasks of Wittgenstein-inspired philosophy can likewise be bifurcated. In an important sense, Wittgenstein denied that philosophy was a cognitive discipline, and denied that the results of philosophy are discoveries on the model of the sciences. Nevertheless, he gave our subject, for the first time in its history, a license to interfere in the affairs of the natural and social sciences. For any form of conceptual entanglement - whether in physics or neuroscience, in empirical psychology or theoretical linguistics, in economics or art history - is a fit subject for philosophical investigation. Wittgenstein's methods and his elucidatory endeavours have given us the tools and the model for identifying and disentangling conceptual confusions in extra-philosophical intellectual disciplines. Here there is much work to be done - it is, after all, virgin territory - and a task that, like medicine, has no end.

The traditional problems of philosophy are, of course, amenable to the methods Wittgenstein bequeathed us. So a further task for those who have learnt from Wittgenstein and who wish to make good use of the ideas that he advanced is to tackle problems that he did not discuss, or perhaps only touched on. The greatest service that can be done to the cause of Wittgenstein's philosophy is to show the fruitfulness of his methods and to demonstrate the manifold ways in which his insights can be applied.

The paper I am about to present is such an attempt. It is conducted, I believe, in the spirit of Wittgenstein's later philosophy, and it makes use of his methods - even though the insights of Aristotle also loom large. In Investigations $\$ 283$ Wittgenstein remarks that only of what behaves like a human being can one say that it has pains. He then adds 'For one has to say it of a body, or, if you like, of a mind which some body has. And how can a body have a mind?' This is a baffling remark, which invites reflection on our curious idiom of having a mind and of having a body, and pro- 
vokes consequent thought on the relationship between the body one has and the mind one has. It is with these themes that the following paper is concerned.

\section{Homo loquens}

Human beings are substances of a certain type - an evolutionary offshoot of the anthropoid apes, whose upright posture and consequent laryngeal changes made articulate vocalization possible. The human species has not only a distinctive appearance and anatomy, posture and mode of locomotion - but also a unique form of life. Our rational powers endow us with a horizon of possibilities of action, thought, and feeling vastly more extensive than anything accessible to other animals. Our ability to reason enlarges the possibility of knowledge and enables us to strive for theoretical understanding. Our ability to act for reasons makes us uniquely answerable for our deeds. We alone in the animal kingdom have knowledge of good and evil, have a conscience, and are susceptible to feelings of guilt, shame and remorse for our wrong doing. It is no coincidence that only human beings can be said to have a soul.

All but the lowliest forms of animal life are conscious. It was a farreaching Cartesian confusion to identify the human mind with the domain of consciousness. Animals undergo periods of sleep or unconsciousness, and duly awaken and regain consciousness. Their attention is caught and held by objects and events in their environment, and it is of these that they become, and then are, conscious. They enjoy or suffer various states of consciousness, such as contentment, hunger, thirst and pain. But only human beings are self-conscious. We can reflect on what we are doing or undergoing, on our reasons for acting, thinking or feeling, on our motives and motivations, on our likes and dislikes, on our character traits and relations to our fellow human beings. Being able to reflect on these, we can often come to understand them better, and in some cases to modify them in the light of our evaluations. We can take into account, in our reasoning and behaviour, facts about ourselves, about our experiences, past and prospective, and about our own character traits and dispositions. For we can not merely feel cheerful or depressed, we can also wonder why we are so feeling, and be pleased or disturbed that we are. We can be aware that we are ignorant or well-informed about something, that we have certain beliefs or doubts, that we have done and undergone various things in the past. Such facts about ourselves may weigh with us in our deliberations and occupy us 
in our reflections; they may be our reasons for acting, feeling or thinking thus-and-so here and now. This is partly constitutive of our being selfconscious creatures.

Other animals have cognitive abilities - they see their prey moving to the left, hear a mouse in the undergrowth, smell a female in heat. They know their young, recognize their call, they know how to do innumerable things, know the way to waterholes, remember where salt is to be found, and so forth. They can think things to be thus and so, and be right or wrong, even though it makes no sense to say of them that they think something to be true or false. When they are wrong, they can sometimes recognise and rectify their error. But the horizon of their thinking is determined by the limits of their behavioural repertoire. They can intelligibly (truly or falsely) be said to think only what they can express in their behaviour. The horizon of human thought is vastly wider. We can think of specifically dated events, of the distant past and remote future. We can think general thoughts, discover and reflect on sempiternal laws of nature, and understand and come to know the timeless truths of arithmetic, geometry and logic. We are blessed, and cursed, with the ability to think of how things might have been, and with the ability to imagine countless possibilities an ability that lies at the heart of our story-telling, and more generally, of art. For, again, we are unique in nature in possessing an imagination, which also makes possible artistic creativity and aesthetic appreciation. Only human beings create works of art, and can be awestruck by the sublime, moved to tears by works of the imagination. Only creatures with imagination can have a sense of humour. We can apprehend the incongruous with laughter, be amused at jokes, and rise above our suffering with irony.

Non-human animals live in the perpetual present. Human beings live in time in a quite different sense. Other animals too have a memory; but only human beings have a past. Human beings have, and can know, a history. In this sense, they can be said to have, and to be able to tell, an 'autobiography'. They can dwell lovingly, proudly or guiltily upon their lives. Many other animals are social creatures, but humans are also socio-historical beings, conscious of themselves as belonging to a social group with a history. Our sense of identity and cultural form of life is bound up with such a history, both actual and mythical. Similarly, only human beings can dwell on, and in, the future and the possibilities it holds. Animal life is full of fear; human life is also full of hope. Only human beings are aware of their mortality, can be occupied or preoccupied with their death and the dead. We are unique among animals in being able to strive to understand our lives 
and the place of death in life. So we are uniquely God-creating, mythgenerating creatures - making the gods in our image, initially to explain the phenomena of nature and appease the forces of nature, later to try to make moral sense of our lives and fortunes by holding out vain hopes (and unwarranted threats) of a life after death.

Whence these unique powers? Alone among animals (with the possible, marginal, exception of chimpanzees), human beings have a crucial, highly specific, innate capacity (a second-order ability to acquire an ability): it is part of our nature to be born with the ability to learn to speak a language. From this, from our animal nature coupled to mastery of a language, all else flows. We are language-using animals - homo loquens, not homo sapiens. Stripped of language, we are but killer apes. All the distinctive powers I have cited are either constitutive of or corollaries of our mastery of a developed language. The horizon of possible thought is determined by the limits of the expression of thought; but with us, unlike other animals, those limits are set by the linguistic expression of thought. If one has mastered the use of tenses and of temporal referring expressions, one can think of the past and future. One can remember not only where - as exhibited in an animal's seeking or homing behaviour - but also when. Non-human animals may prepare for the future - bury food for later consumption, build dams or dig burrows, but only man can plan for the future.

If a creature has mastered a language with logical connectives and quantifiers, then and only then is it possible for it to conceive of general truths, to think both of how things are and how they are not, to think both of what exists and of what does not exist, to think conditional thoughts, and with the aid of tensed verbs and modal expressions, counterfactual thoughts. With our powers of linguistic representation go also our powers of pictorial representation - no other animal can make an image. Some other animals can recognize an image. No other animal can recognize an image as an image - if a cat paws at a picture of a mouse, it is not trying to deface an image. Only a language-using creature can apprehend the 'eternal truths' of mathematics. That is because such truths are essentially norms of representation that find their ultimate rationale in rules for the transformation of empirical sentences concerning magnitudes.

Our linguistic skills not only extend the limits of thought, they also shift the horizons of desire and will and introduce the 'if only-s' that haunt us with regrets and remorse, and gild our wishes and longings. Non-language using animals may now want food or drink, but cannot now want food or drink next Wednesday. Animals have purposes, pursue goals, and opt for 
different ways of attaining them. But the trajectory of their desires reaches no further than their behavioural repertoire can express, and the objects of their desires are constrained by their limited non-linguistic recognitional abilities. They can opt for one or another alternative, but not deliberate. There are reasons why an animal acts as it does, but, only in the most tenuous of senses can we say that they have reasons for acting as they do. Only a language-using creature can reason and deliberate, weigh the conflicting claims of the facts it knows in the light of its desires, goals and values, and come to a decision or make a choice in the light of reasons. In so far as non-human animals can be said to decide, such animal decision is not a matter of calling a halt to a process of reasoning, of weighing the pros and cons of a course of action and coming to a reasoned conclusion. It is only a matter of terminating a state of indecision.

A creature that has mastered a language with demonstrative and indexical devices, including the personal pronouns, can acquire the self-reflexive cognitive and cogitative abilities that constitute self-consciousness. To have grasped the meanings of typical psychological verbs requires both knowledge of the grounds for third-person ascriptions and mastery of the groundless first-person use. Only if a speaker has mastered the Janus-faced use of pivotal psychological verbs, is he in a position to reflect on his own sensations, attitudes and feelings, on his thoughts, plans and projects. Only if he has learnt to give reasons can he be in a position to reflect on the reasons he has. Only if he can reflect on his reasons and probe his motives can he strive for that self-knowledge that is attainable by self-conscious creatures. Hence too, only human beings can wrap themselves in the tattered cloak of self-deception.

\section{Mind}

That we speak of ourselves as having a mind is a crucial aspect of our discourse about human beings. English idiom is rich in phrases incorporating the word 'mind'. These are far from universal (many languages, even closely related languages such as German, do not have a word that pre-

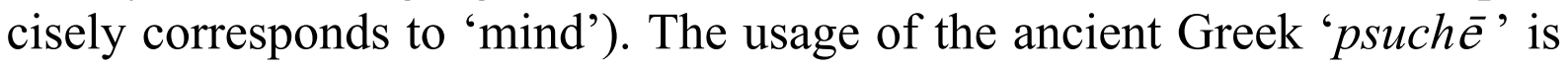
by no means homologous with that of the word 'mind', and the ancient Hebrew terms 'nephesh', 'neshama' and 'ruakh' are likewise dissimilar. Nevertheless, there is much to be learnt about the mind-body problem from reflecting on our talk of the mind, even if not all of what is to be learnt is directly relevant (but may nevertheless be indirectly relevant) to the psuche 
-soma problem or to the nephesh-goof problem. Our concern is with the mind-body problem, hence with the concepts of mind and body. The only way to investigate these concepts and their logical relationships is to investigate the words that express them.

Careful scrutiny of the use of the word 'mind' will enable us to resist, at least pro tempore, the temptation to answer the philosophical question 'What is the mind?' by giving a definition. 'The mind' being a nominal, 'What is the mind?' is commonly construed as 'What sort of entity is the mind?' But this is as pernicious a question as 'What sort of entity is a number?' It raises the wrong kind of expectations, and sends us along the wrong paths before we have had a chance to get our bearings. So the first step to take is to examine the use of the noun 'mind'.

The English word 'mind' is etymologically derived from expressions in Indo-Germanic languages that were associated primarily with memory, thought, opinion, and intention. To hold something in mind is to retain it in memory, to turn one's mind to something is to begin thinking about it, to know one's mind is to have formed one's opinion, to make up one's mind is to decide. It is noteworthy that these idioms are largely associated with the exercise of the powers of the intellect and will. English idiom ramifies in further directions. At the most general level, the mind is associated with intellectual faculties: a person is said to have a powerful, agile, subtle or devious mind if he is skilful, quick and ingenious at problem solving, or if his solutions, plans and projects display subtlety and cunning. Hence too, it is connected with appropriate intellectual virtues and vices: a person has a tenacious, idle, vigorous, judicious or indecisive mind according to the manner in which he grapples with problems requiring reflection and according to the typical upshot of his reflections. A person is of sound mind if he retains his rational faculties, and out of his mind if he thinks, proposes or does things that are irrational. He is not in his right mind if he is distraught, and he has lost his mind if he is bereft of his rational faculties.

The second step is to derive some morals from these reminders of linguistic idiom. First, each such use, as is evident from the above examples, is readily paraphrasable without the word 'mind'. All that is needed is a corresponding psychological predicate predicable of the human being. In this sense, reference to the mind is eliminable without loss. Talk of the mind, one might say, is merely a convenient façon de parler, a way of speaking about distinctive human faculties and their exercise. Of course, that does not mean that the mind is a fiction. It does not mean that human beings do not have minds of their own - which would be true only if they 
were pathologically indecisive. Nor does it mean that people are mindless - which would be true only if they were stupid and thoughtless. It would be quite wrong to suggest that 'minds should be written off as an intellectual loss. ${ }^{1}$ What is true (and perhaps what was intended) is that the philosophical construal of the mind as an immaterial substance is incoherent. It is similarly mistaken to suggest that our minds 'are pretend entities', that the agency of the mind 'is not a real agency ... but an agency we pretend exists, and the qualities of which we pretend explain the behaviour'. ${ }^{2}$ It is true that the mind is no agent, but we no more pretend that our mind is an agent than we pretend that our character is an agent; and we no more pretend that our mind is an entity than we pretend that our abilities are entities. Rather, in superficial reflection on the mind, we are easily misled by our language into thinking that the mind is a part of a human being, that it is an immaterial substance - the person or self, and we are prone to ascribe agency to the mind thus conceived. That is a conceptual confusion. But our rich and elaborate talk of the mind is not at all like our talk (and pretence) of Father Christmas. To repeat, to say that our ordinary talk of the mind is a mere façon de parler, or that it is a logical construction, is not to say there are no minds. On the contrary, it is to say that there are, only that they are not kinds of things. The mind, it might be said (adapting a phrase from Wittgenstein), is not a nothing, but it is not a something either.

Secondly, it is obvious that in the various idioms one is not speaking of one and the same thing, called 'the mind'. When we say that someone changed his mind, that he has a dirty mind, and that he has turned his mind to a certain question, we do not imply that there is one thing: a mind, which has changed, is dirty and has been turned. We are indeed speaking of the very same thing, namely the human being, and from case to case, and phrase to phrase, we are saying different things of the human being.

Thirdly, it is evident that the question of whether the mind is identical with the brain, under one interpretation, becomes transparently absurd, since the mind is not a kind of entity that might be identical with anything. The question is accordingly transformed into a different one: can psychological attributes be identified with neural states, processes or events in the brain. I shall not discuss this question here.

Fourthly, the very distinctive range of idioms appertaining to the mind suggests that it is not because we have minds that psychological predicates apply to us, but rather because a fairly specific sub-set of psychological

\footnotetext{
${ }^{1}$ Squires 1970, 355 .

${ }^{2}$ Hunter 1986, 442, 444.
} 
predicates apply to us that we can be said to have minds. That fish can see and hear, that birds can be frightened of a cat, that cats can want to catch a bird - all of which Descartes denied - does not show that he was wrong to deny that they have minds.

Fifthly, although we speak of someone's having a quick, agile, original mind, or a slow, idle, and dull one, it is a categorial mistake to suppose, as Reid (and others) did, that the mind is 'that in [man] which thinks, imagines, reasons, wills'. We ascribe agile, devious, imaginative minds to human beings, but do not, on the whole, speak of the mind as if it were an agent, although we do sometimes speak of it as if it were a patient, as when we say 'my mind is paralysed (numb)'. It is not my mind that thinks, imagines, reasons or wills, it is I. It is not my mind that makes up its mind or decides, that changes its mind or reverses its decision, that has half a mind, or is inclined, to do something - it is I, a human being. It is not the mind that feels pain, perceives, knows, is conscious of this or that, feels happy or upset, desires this or intends that. It was a Cartesian confusion to ascribe the whole range of psychological attributes to the mind. That incoherence is multiplied by present-day materialists' identifying the mind with the brain, and ascribing the same range of predicates to the brain.

What then is the mind? If a definition is meant to provide a rule for the current use of a word, then there is no useful definition of 'the mind', although from idiom to idiom we can explain what is meant. But if we cannot fruitfully define 'mind' in this sense of 'definition', we can ask what must be true of a creature for it to be said to have a mind. It is evident that it is above all human beings that are the subjects of this array of idioms. What then is it about human beings that inclines us to invoke the whole panoply of the language of the mind? Surveying the range of characteristic English idioms yields interesting results. They are clustered around forms of thought, opinion, recollection and will that are possible only for language users. For the vast majority of idioms of the mind are concerned with the intellect and will, their exercise, and the traits and dispositions that exemplify these faculties. Talk of the mind is concerned with the distinctive rational powers of human beings and their exercise.

Once this is clear, it becomes evident that the domain of the idiom of 'mind' coincides roughly not with that of the Cartesian mind - the domain of consciousness, but with that of the Aristotelian rational psuche. The Aristotelian psuche $\bar{e}$ is not a kind of entity, and the question of whether the organism and its mind are one thing or two is, according to Aristotle, as absurd as the question of whether the wax and the impression on it are one 
thing or two. The possessor of a mind is an animal of a certain kind, namely a human being. To have a mind is not to be in possession of a kind of entity. It is rather to possess a distinctive range of powers.

Aristotle's profound account of psuche $\bar{e}$ was concerned with demarcating the animate from the inanimate, with the classification of the animate into (very general) categories according to the classes of powers that characterize living beings - the vegetative psuch $\bar{e}$ and the sensitive psuche being the powers that characterize plant and non-human animal life. What is distinctive of humanity over and above the powers of the vegetative and sensitive psuch $\bar{e}$ is the rational psuch $\bar{e}$ - the ability to reason and to act for reasons. To have a mind, according to the Aristotelian-scholastic tradition, is to have an intellect and rational will. It is to be able to reason, to apprehend things as affording reasons for thinking, feeling and acting. It is to be able to deliberate, decide or choose what to do or believe, and to modify one's feelings and attitudes, in the light of reasons. These farreaching and complex powers are corollaries or consequences of being language-users.

\section{The body}

The nature of the mind has been obsessively discussed since Descartes, and examined in detail by analytic philosophers of the twentieth century. It is, however, surprising how little attention has been given, in the analytic tradition, to the ways in which we think and speak about our own bodies. It has generally been assumed that the concept of the human body is unproblematic. But that is wrong.

I have such-and-such a body, just as I have such-and-such a mind. Am I my body? Surely no more than I am my mind. Am I then a third thing? Is the body of a living human being the same as the body he leaves behind when he dies, that he leaves to science or wishes to be cremated? - Same what? It is not the same corpse, since the body of a living human being is not a corpse. It is not the same living body, since the living body is not to be cremated. Same body? - that depends on what exactly is meant by 'body' and on whether 'a person's body' is a covering sortal for such statements of identity.

NN has a head, two arms and two legs. Does his body have a head, two arms and two legs? 'Of course!', we are inclined to say. But perhaps we should take things slowly. If NN went to war, and lost his left leg on the Normandy beaches, it can be said of him 'Poor fellow, he lost his left leg 
in the war'. Can it be said, 'Poor fellow, his body lost its left leg in the war'? If NN dies, we may say to the undertaker: 'His body has only one leg, he lost his left leg on the Normandy beaches (not: 'it lost its left leg on the Normandy beaches'). I can have my mother's eyes and my father's nose. Can I have my body's nose? Does my body have a nose? Presumably only if it has a face? Can we speak of my body's face? - Well, it is perhaps not false that it has a face; but it is not obviously true either. (And if it is indeterminate what we should say, that too is an important datum.) NN had a quick mind and a noble soul. Did his body have a quick mind and a noble soul? What would a person's body do with a mind? or a soul? The thickets through which we must find a pathway are dense. Let us first generalize the puzzlement.

What is it to have a body? What has to be true of a being for it to be said of it that it has a body? - after all, trees and plants certainly do not have bodies. My body cannot think, or speak, and it cannot walk or run; so, what attributes can the body of a living human being have? We have two arms and two legs. These are parts of the human being, of the human organism. By extension, they are also said to be parts of the body a human being is said to have. We speak of ourselves as having a body, and are prone to think, by analogy with having arms and legs, that the body we have is likewise a part of ourselves - the material part, the other part being the mind. That is a natural movement of thought. But in philosophy what is natural is to err. So we must investigate how the mind that a human being has is related to the body that he has.

The word 'body' in English has many different uses. At its most general, a body is simply a spatio-temporal material continuant. In this sense, human beings are bodies, as are plants and other animals. They are differentiated from inanimate (mere) material bodies in virtue of being alive. That marks a qualitative difference (as Aristotle emphasized, and Descartes denied), which has left its mark on our conceptual scheme - not because our remote ancestors were so sapient, but because the primitive human reactions to what is alive as opposed to what is dead, and to what is alive as opposed to what is inanimate, are so profoundly different.

The animate body that a human being is is the human organism. Clearly, a human being does not have the organism that he is. So the body - the organism - that he is, is not the body that he has. The human organism has parts: head, torso and limbs, which are parts of the human being.

It should be noted that we also use the term 'body' to refer to the trunk or main bulk of a living thing. A quite different use is to refer to a corpse, 
as when we say that the dead monarch's body is lying in state, that NN's body is in the next room, or that the battlefield was strewn with bodies of dead soldiers. A number of interesting features attend this use. First, it is striking that not all modern languages employ the same word to refer both to the body a person has and to the body he leaves behind. German, for example, uses 'Leib' (a cognate of 'Leben') or 'Körper' (derived from 'corpus') to signify the living body, and 'Leiche' to signify the corpse. Secondly, it is unclear what creatures can be said to leave a corpse when they die. Certainly a dead tree or plant is not the corpse or body of a tree or plant. The sardines we buy at the fishmongers are not corpses of sardines. A dead horse or cow may be a carcass, but not a corpse. Thirdly, it is the human being - the mortal man - that dies, not his body. Leonidas died fighting valiantly at Thermopylae. It was he, not his body, that was killed. What was left upon the stricken field was his corpse - his remains. Cleopatra killed herself, but it is doubtful whether one can cogently say that the beautiful body she had then became a corpse. Nor can one say that the alluring body she had is dead - she is dead, and what is left is her corpse. Fourthly, we are inclined to assent to such assertions as 'When I die, I shall no longer exist, but my body will persist for a while', and perhaps even to 'When I die, my body will cease to be me, and I will no longer exist' ${ }^{3}$. But the body I have when I am alive cannot, as we shall see, be said to be me, and the body I leave behind, i.e. my corpse, is not the living body (the animate spatio-temporal continuant) that I am. A living body is not the same anything as a corpse - no common sortal subsumes both. Of course, they can be said to be the same 'spatio-temporal continuant' - but that is no sortal. The corpse is the dead human being, and a dead human being is no more a human being than a counterfeit five pound note is a five pound note.

The most common use, and the one most pertinent to our concerns, signifies the physique or figure of a human being, the appearance, condition of health and fitness. Commonly 'body', thus used, goes with a modifying adjective, as in 'a supple / healthy / frail / crippled / athletic / powerful / muscular / beautiful / attractive / sexy / sensual / body'. Often it is used to draw a contrast with the person's mind, as when we say 'His body is frail, but his mind is as active as ever' (i.e. he is physically frail but mentally alert) or as when young males, ogling at an alluring young woman on the beach, say 'Look at her body!' (i.e. look at her figure) and as when we ob-

\footnotetext{
${ }^{3}$ Kenny 1988, 24.
} 
serve that a man has a powerful body (i.e. a powerful physique). It is this use that we need to examine.

What ranges of things can be attributed to my body or NN's body? what can a person's body be? It can be suntanned all over, be white through lack of exposure to the sun or red from excessive exposure. It may be painted blue (like the bodies of the ancient Britons), gleam with oil (like the bodies of the ancient Greeks in the palaestra), or be covered with dust, mud or blood. It may be badly lacerated or covered with mosquito bites. It may be tense or relaxed, strong or weak, fit or out of condition, muscular and hard or fat and flabby. It may be paralysed or shaking uncontrollably in shock. And it may be beautiful or ugly, graceful or ungainly, gangly or dumpy.

If a person's body is suntanned all over, then that person is suntanned all over. If someone has a powerful, badly scarred body, then he is physically powerful and badly scarred. And if someone's body is out of condition then the person is out of condition. It is tempting to conclude that anything true of a person's body is also true of the person. That is generally true, but we should note exceptions. If Daisy's body is beautiful (if she has a beautiful body), it does not follow that she is beautiful - for we may continue: 'but she has an ugly face'. One may admire her body without admiring her (she may be a dreadful person).

It is noteworthy that our form of discourse about our body licenses describing it, as well as our parts (limbs, head and torso) as sensitive. My leg may itch, my swollen hand may throb, and my body may ache all over. It was mistaken of Descartes to suppose that the human body is an insensate biological 'machine'. It was mistaken to draw the boundary of mind and body between sensibility (and other forms of Cartesian thought) and insensate matter. We allocate sensation to the living body no less than to the human being - it is an aspect of the sensitive psuche Localized sensations such as itches, pains and tickles are perfectly literally in the body; 'I have a pain in my foot' is no metaphor. But they are not in the body in the manner in which pins or bones are. We specify their bodily location when identifying such sensations, and we point to the place of an ache, tickle or itch when asked where it aches, tickles or itches. We assuage the sensation, rub or nurse the part of the body that hurts. Bodily sensations typically have a physical cause. Its locus is typically, but not necessarily, the place of the sensation. Hence we contrast physical pains with the pains of grief, distress, and other forms of mental suffering that have no somatic location.

Sensations then are in the body. What is the relationship between the 
sensitivities of my body and the sensations I have? If my body aches all over, I ache all over, if my back aches, then I have a back-ache, and if my hand hurts, then I have a pain in my hand. But my back does not have a back-ache, and my hand does not have a pain, let alone a pain in it. If I have hurt my hand, then I have hurt myself - but my hand has not hurt itself.

What else cannot be said of a living person's body? A person's body is not the subject of voluntary and intentional predicates. My body may tremble or be paralysed, but it does not move itself, it does not walk, jump or run. Nor is it the subject of perceptual, cognitive, cogitative or affective predicates. A human being's body does not see or hear, know, believe or think, feel cheerful or angry. It may drip with sweat, but it cannot weep. It may be unfit, but it cannot take exercise. Since a person's body is logically excluded from being the subject of these distinctive attributes, we are inclined to think that something other than, and distinct from, his body must be their subject, namely his mind. But it is the human being that is the subject of experience and the agent of action. What then is the relationship between a human being and the human being's body?

\section{The relationship between human beings and their bodies}

It has been suggested that a human person is constituted by his body. The relation between a human being and his body, it is suggested, is the same as that between a statue, such as Michelangelo's David, and the piece of marble that constitutes it. ${ }^{4}$ But a statue is neither constituted by a piece of marble, nor is it a piece of marble, any more than a cake is constituted by a piece of cake or is a piece of cake, or a car is constituted by a piece of metal or is a piece of metal. 'Piece' is one of the most general partitives. It applies both to abstract and to concrete non-count nouns (as in 'a piece of news' and 'a piece of bread'), by contrast with such type-specific partitives as 'grain', 'bar', 'drop', 'loaf', 'lump', 'sheet', 'slice', 'sliver', 'strip'. A desk is not a piece of wood, although it may consist of pieces of wood and also may have been made out of pieces of wood. The David was made out of a large piece of marble already worked and then abandoned by Agostino di Duccio. It is made of, consists of, marble (more than a ton of it), but it does not consist of a piece of marble. Nor is it constituted by a piece of marble, any more than Rodin's Balzac is constituted by a chunk of bronze

\footnotetext{
${ }^{4}$ Baker 2000.
} 
or Leonardo's Sforza monument was constituted by a lump of clay. A human person does not consist of a piece of flesh. He is made of flesh and blood, but not made out of flesh and blood. And he is not constituted by his body.

A quite different conception is vehicular. One might be tempted to claim that 'my body is the vehicle of my agency in the world'. It is tempting to say that my body is the body the arms of which rise when I raise my arms, the legs of which move when I walk, and that it is the body with the eyes of which I see when I open my eyes. The temptation should be resisted for two reasons. First, my relation to my body is not that of a driver to his car (my car is indeed the car the front wheels of which turn left or right when I turn the steering wheel). When the driver turns the steering wheel, he makes it go round, but when he raises his arm he does not make it rise, or cause it to rise. When he turns the steering wheel with his hands, he brings it about that the steering wheel goes round and the car changes course, but when he raises his arm, he does not bring it about that his arm rises. A person controls his body, but not as a driver controls his car. Nor is he in his body as a driver is in his car - but not because he is 'more closely intermingled with it'.

Secondly, while it is true that I see with my eyes and walk with my legs, it is far from obvious whether we can speak of my seeing with my body's eyes, and walking with my body's legs. My head, torso and limbs are parts of me - of the human being I am. I have a body, and my limbs are parts of my body. But my body does not have a body, and although my arms and legs are parts of my body, my body cannot be said to have arms and legs (although a corpse can). Although the mereology of the human being is homologous to the mereology of the body he has, it is the human being that has arms and legs, not the body he has - that is, we do not, by and large, extend the very peculiar form of representation of possession from the human being to the living body that is his. My leg may be bruised, but we would not say that my body's leg is bruised. I may suffer from meningitis, but we would not say that my body's brain suffers from meningitis. These are forms of words that have been given no use - and it is best left that way. Could we use them? Of course - if we changed a great deal of the surrounding grammar.

One might try to clarify the relationship between a human being and his body by reference to the dependency of perceptual experience upon facts

\footnotetext{
${ }^{5}$ Swinburne 1984, 22.
} 
about the body. Whether one sees anything at all depends on whether one's eyes are open. What is visible to one, it is said, depends on where one's body is located, on the direction in which one's head is turned and on how one's eyeballs are oriented. Such facts of experience-dependency might be thought to explain why the 'possession' of a particular body should be ascribed to the same thing as states of consciousness. They might be thought 'to explain why a particular body should be spoken of as standing in some special relation - called "being possessed by" - to that thing', that human person. They are said to explain why a subject of experience should have a very special regard for just one body, why he should think of it as unique and perhaps more important than any other. ... they might even be said to explain why, granted that I am going to speak of one body as mine, I should speak of this body as mine. ${ }^{6}$

This passage is subtly mistaken. We may grant (with deliberate rephrasing) that the visual experiences a human being has depend on where that human being is, on the state of his eyes and on the direction in which he is looking. But such truths do not explain why 'a particular body' should be spoken of 'as standing in some special relation - called "being possessed by" to that human being. The body a human being has is not a body he literally possesses, any more than the birthday, the wife, and the mind he has, are things he possesses. To think otherwise would be to confuse the form of representation with what is represented. One may have a house, a ticket to the opera or a copyright. These one can sell or give away - and once sold or given away they are no longer one's own, but belong to another. One can sell one's body - but to do so will not leave one bodiless. (Similarly, when Faust sells his soul to the devil, he is not left soulless.) To sell one's body is to sell sexual services; it leaves one bereft of certain freedoms, not of a body. Is not having a body logically akin to having two arms or legs? No; for I can lose an arm or a leg, but I cannot lose my body. Of course, someone may find my body - but then he needn't return it. (And if I lose my mind, there is no point looking for it in the lost property office.) Could one not say that the relationship between a human being and his body is one of ownership, but that unlike humdrum relations of ownership, the possession of a body is inalienable? No; something can be inalienably possessed only if it makes sense for it to be alienated.

It is mistaken to suggest that the various forms of the experiencedependence of a human being on his location, orientation and the condition

\footnotetext{
6 Strawson 1959, 93.
} 
of his sense organs 'explain why a subject of experience should pick out one body from among others, give it, perhaps, an honoured name and ascribe to it whatever characteristics it has' (ibid.). For, to be sure, a subject of (conceptualized) experience does not 'pick out one body from among others' and call it his own. One has no choice, and could have no choice, in what to speak of as 'my body'. Furthermore, nothing could explain 'why, granted that I am going to speak of one body as mine, I should speak of this body as mine'. As an English speaker, I am going to use the English phrase 'my body'; I speak of my body as aching, showing its age, fit or out of condition. But I do not speak of 'one body among others' as mine. If I say 'my body is aching all over', no one could ask 'Which body is yours?'.

It is tempting to claim that 'that which one calls one's body is, at least, a body, a material body. It can be picked out from others, identified by ordinary physical criteria and described in ordinary physical terms. ${ }^{7}$ But this is misleading. 'Which body is my body?' has little use, other than to ask what 'my body' means. 'This [pointing reflexively] is my body' has no use in picking my body out from others, although it might be used to explain the phrase 'my body'. The material body, the animate spatiotemporal continuant made of flesh and blood, that can be picked out (by others), identified and described in 'physical terms', is me. But I don't call that which I am 'my body'. I am a body; but I don't have myself, don't have the body I am. We sometimes speak of ourselves as being embodied, but mistakenly so. It is but one step from this figure of speech to thinking of ourselves as residing in our body. It would be far less misleading to think of ourselves, with Aristotle, not as embodied but as ensouled (empsuchos) - endowed with the powers that characterize humanity.

We have seen that the mind is not a kind of entity, that our customary talk of the mind is no more than an abstraction from our talk of human be-

\footnotetext{
${ }^{7}$ Strawson 1959, 89. To be sure, if one claims that 'that which one calls one's body is at least a body, a material body', then one lays oneself open to the question of how the body one has is related to the body (the organism) one is? Then one might indeed wonder whether the body one has occupies the same space as the body one is. But that would be akin to wondering whether, given that doing something for my sake is doing something for me or on my account, the sake I have is identical with me or with the account I have. All talk of 'my body' is no more than an idiomatic way of speaking of the somatic characteristics of the human being that I am. It is not a way of talking of anything other than myself nor is it a way of talking of some subordinate part of myself. (Remember that to say of someone that he has a decisive mind is just to say that he is decisive - it is not to say that there are two decisive things: him and his mind.)
} 
ings, of their intellectual, mnemonic and volitional abilities and their exercise. It should by now be evident that our parallel talk of our body is in a like manner largely derivative from our talk of human beings. We have and exercise an array of cognitive, cogitative and volitional powers that we exhibit in our behaviour. As agents of this kind, we are said to have a mind. We likewise have a variety of corporeal determinables - a physique, a figure, physical appearance, susceptibility to sensation, degrees of fitness (ability to engage in physical activity) and health. As such agents, with a mind that is manifest in corporeal activities and reactions, we are also said to have a body, and can be described as having such-and-such a body (powerful, muscular, lithe, graceful). We describe ourselves thus when we wish to focus upon such attributes, and to manifest our attitudes to them. For we may be proud of our body (if it is fit and beautiful) or ashamed of it (if it is fat, flabby and ugly), admire the beautiful bodies of the young and be shocked by the mutilated bodies of the injured. We may be comfortable with our body, or ill at ease with it (e.g. if we are pathologically obsessed with our physical appearance and condition). Being self-conscious creatures, much preoccupied with sexual attraction and commonly given to degrees of hypochondria, it is hardly surprising that we should think a great deal about our physique, aesthetic appearance, attractiveness, our physical condition.

In the sense in which 'a body' is a material spatio-temporal continuant, then, of course, human beings are bodies - although this is a quasitechnical use of 'body', and not something that can be said unmisleadingly or inoffensively in extra-philosophical discourse. Material spatio-temporal continuants may be inanimate or animate. Those that are animate are organisms of varying degrees of biological complexity. Human beings are highly complex organisms, and in this sense too are bodies. Being a body in this sense, being an organism, implies being a body in the most general sense. We further speak of ourselves as having a healthy, ageing, weak or strong body. To be sure, only a creature that is a body in the previous sense can thus be said to have a body. The moot question is: what has to be true of a creature that is an animate spatio-temporal continuant for it to be said to have such-and-such a body? The most coherent answer is: only if it can also be said to have such-and-such a mind. No doubt we sometimes extend the idiom to other animals, by analogy with ourselves. We may well say of an injured horse that its poor body was terribly lacerated, just as we may say of a stubborn horse that refused to do what we want it to do that it has a mind of its own. Such uses are harmless extensions, but they show little 
about the rich web of connections in the paradigmatic, human, case. One might also say that the idiom of having a body is a formal mark of advanced sentient life that also leaves a corpse on death.

So, talk of our body is no less derivative from, or parasitic on, talk of the human being as a whole than is talk of our mind. We say of Jack: 'He has a stocky body, handsome face, lively mind and kind heart'. Until we stop to think about it, it would not occur to anyone that we are doing anything other than talking about a single human being - specifying a variety of different modes that our complex species may exemplify in a variety of complex ways. But, like Augustine, once someone asks us, once we stop to think, we become entangled in the web of words.

What then is the relationship between the mind and the body? The mind/body problem is insoluble. For it is a hopelessly confused residue of the Platonic/Augustinian/Cartesian tradition. It cannot be solved; but it can be dissolved. The mind is not an entity that could stand in a relationship to anything. All talk of the mind that a human being has and of its characteristics is talk of the intellectual and volitional powers that he has, and of their exercise. The body that a human being is, the living organism, has and exercises those distinctive intellectual and volitional abilities that we speak of when we speak of people's minds. But the body that a human being is said to have, when we speak of human beings as having beautiful or athletic bodies, is not the kind of thing that could be said to possess intellectual and volitional abilities. For we speak of a human being's body thus when we focus upon corporeal characteristics that the human being in question has. These characteristics, the very distinctive range of corporeal features of a human being that we assign to the body he has, are not the kinds of thing that could make up their minds, call things to mind or change their minds.

The mind a human being has and the body he has are not the kinds of things that could stand in any relationship to each other in the sense in which Jack and Jill (or London and Paris, or a man and his property) may stand in a relationship to each other. The apparent relationship is comparable to the 'relationship' between the meaning of a word and the phonemes into which the word can be analysed - both being abstractions from the meaningful word in use. The English word 'cat' has a meaning (it means the carnivorous quadruped Felix domesticus), but does not stand in a relationship to its meaning, any more than I stand in a relationship to my mind. The phoneme koet neither has a meaning nor stands in a relationship to a meaning - it is a phonologists' abstraction from the meaningful English 
word. Similarly, my body does not have a mind and does not stand in a relationship to my mind. ( $I$ have a mind - and a body; what would my body do with a mind?) One might compare the question of how my mind is related to my body with the question of how the value of five pounds is related to the colour of the paper on which the note is printed. For here too one might explain that the five pound note has a value of five pounds, but the colour of the paper on which the note is printed does not stand in any relationship to the value of five pounds. So the mind-body problem as traditionally conceived simply evaporates.

\section{REFERENCES}

Baker, L.R. 2000 Persons and Bodies - A Constitution View, Cambridge: Cambridge University Press.

Hunter, J.F.M. 1986 "The Concept 'Mind”, Philosophy, 61, 439-51.

Kenny, A.J.P. 1988 The Self, Milwaukee: Marquette University Press.

Squires, R. 1970 “On One's Mind”, Philosophical Quarterly, 20, 347-56.

Strawson, P.F. 1959 Individuals, London: Methuen.

Swinburne, R.G. 1984 Personal Identity, Oxford: Blackwell. 